\title{
Proceeding
}

Supplementary Issue: Autumn Conferences of Sports Science. Costa Blanca Sports Science Events, 18-19 December 2020. Alicante, Spain.

\section{Effects of a set of physical exercises to improve conditional capacities in seventh grade students of the Pedro Nufio Technical Vocational Institute}

\author{
RAUL ANTONIO GAITAN-AMADOR ${ }^{1}$, RAÚL ORLANDO FIGUEROA-SORIANO², NAHUM DAVID \\ MARTÍNEZ-SARAVIA ${ }^{3}$ \\ ${ }^{1}$ Danlí Regional Centre, National Autonomous University of Honduras, Tegucigalpa, Honduras \\ 2University Management Board, National Autonomous University of Honduras, Tegucigalpa, Honduras \\ ${ }^{3}$ Faculty of Humanities and Art, National Autonomous University of Honduras, Tegucigalpa, Honduras
}

\begin{abstract}
The research dealt with conditional physical abilities in the class of education, where through a set of exercises the physical condition of the students; In this sense, it starts from the problems presented from the curriculum National Basic of Physical Education of Honduras which offers limited alternatives for the development of conditional capacities. The study of the effects of a set of exercises is offered taking into account the tests of Physical efficiency established in the seventh grade groups of the Pedro Nufio Educational Centre in order to establish a work profile for the orientation and dosage in the class and raise an evaluative profile on the criteria of this ability in the students.
\end{abstract}

Keywords: Physical abilities; Strength; Endurance; Speed.

Cite this article as:

Gaitan-Amador, R.A., Figueroa Soriano, R.O., \& Martínez Saravia, N.D. (2021). Effects of a set of physical exercises to improve conditional capacities in seventh grade students of the Pedro Nufio Technical Vocational Institute. Journal of Human Sport and Exercise, 16(2proc), S825-S836. doi:https://doi.org/10.14198/jhse.2021.16.Proc2.68

Corresponding author. Danli Regional Centre, National Autonomous University of Honduras, Tegucigalpa, Honduras. https://orcid.org/0000-0001-7920-226X

E-mail: raulgaitan86@gmail.com

Abstract submitted to: Summer Conferences of Sports Science. Costa Blanca Sports Science Events, 25-26 September 2020. Alicante, Spain.

JOURNAL OF HUMAN SPORT \& EXERCISE ISSN 1988-5202

(c) Faculty of Education. University of Alicante

doi:10.14198/jhse.2021.16.Proc2.68 


\section{INTRODUCTION}

The development of physical capacities is of constant systematic studies in order to improve it in different contexts such as physical education, where achieving a good physical condition for the development of students is priorities for both teachers and educational centres. Within the functions of the Educational Centres at the secondary level, the treatment of the contents conditional capacities (Strength and speed) is handled. Aspect of analysis of this inquiry, which is evidenced in its diagnosis, has not been treated in the best way up to the step (7th grade) to which the students under study have reached in this year 2019, thus generating a deficit of work on their stated capacities showing the following data:

Dynamic Arm Strength (20 sec Chest Test): 250 are below average and 70 are low.

Dynamic Abdominal Strength ( $20 \mathrm{sec}$ Abs Test): 230 is at a lower level than average 45 and at a low level 45.

Translation speed ( 30 meter speed test): 245 are at a level below the average and 75 are at a low level. As it can be seen, there are difficulties in the capacities of these students with regard to the work of conditional capacities in the 7 th grade in both genders.

From the investigative point of view, it has been treated by scholars such as Platonov (2001), Barrios and Ranzola (2001), Aschwer (2000) who have contributed concepts that have been systematized to date in terms of physical capacities.

For example, strength represents the overcoming of a certain external resistance with great muscular effort, it is considered the most important for man, since it is a premise for the development of other capacities. (Barrios and Ranzola 2001).

Regarding resistance, it is assumed as a capacity that shows when performing a lasting physical activity without diminishing its performance, it is also expressed as the body's resistance capacity against fatigue. (Aschwer 2000).

And speed as an indispensable conditional ability to perform motor actions in the shortest possible time under given conditions. (Platonov 2001).

Once the conceptions are assumed, it is important to materialize the contribution, in solutions that can be established in social practice; Therefore, our study intends to validate by experts, taking into account the Chanlat matrix, the effects of a set of physical exercises to improve conditional capacities (Strength and speed) in seventh grade students of the Pedro Nufio Technical Vocational Institute of Danlí in the year 2019.

The results obtained will be of vital importance for the systematic work in the organization of the process of development of the physical capacities that the teachers of said educational centre carry out as a task.

\section{METHOD}

The pre-experiment will be taken into account as a procedure in the study, taking into account the criteria of Sampieri and Collado (2014) which will allow to know the effects of a set of physical exercises to improve the conditional capacities in seventh grade students at the Vocational Institute Technician Pedro Nufio de Danlí. 
The scope of the research is explanatory in nature since variables are associated through a predictable pattern for a group or population. In other words, it will be investigated using the following variables: $(X)$ Set of Exercises and the variable $(\mathrm{Y})$ Conditional Capacities (dynamic arm and abdomen strength and translational speed.

\section{Population and sample}

The sample is of a non-probabilistic type directed, the selection procedure by quota intentionally, made up of 320 students of the seventh grade of the morning session of the year 2019. (200 men and 120 women) from the Pedro Nufio Technical Vocational Institute of the city of Danlí Department of El Paraíso in 2019.

Table 1. Variable of dynamic arm strength in women.

\begin{tabular}{lccccc}
\hline Variables & Dimensions & Indicator & Items & Analysis unit $\begin{array}{c}\text { Instrument or } \\
\text { technique to use }\end{array}$ \\
\hline & 1 & $\leq 7$ & Very low & & \\
Dynamic arm & 2 & $8-10$ & Low & & \\
strength capacity & 3 & $11-12$ & Lower than average & & \\
in women. & 4 & $13-14$ & Half & 120 People & Strength test \\
& 5 & $15-16$ & Above average & & \\
& 6 & $17-18$ & High & & \\
& 7 & $>19$ & Very high & \\
\hline
\end{tabular}

Table 2. Variable of dynamic arm force in men.

\begin{tabular}{lccccc}
\hline Variables & Dimensions & Indicator & Items & Analysis unit & $\begin{array}{c}\text { Instrument or } \\
\text { technique to use }\end{array}$ \\
\hline & 1 & $\leq 3$ & Very low & & \\
Dynamic arm & 2 & $4-7$ & Low & & \\
force capacity & 3 & $8-9$ & Lower than average & & \\
in males. & 4 & $10-14$ & Half & 200 People & Strength test \\
& 5 & $15-16$ & Above average & & \\
& 6 & $17-21$ & High & & \\
& 7 & $>22$ & Very high & & \\
\hline
\end{tabular}

Table 3. Variable of dynamic abdominal force in women.

\begin{tabular}{lccccc}
\hline Variables & Dimensions & Indicator & Items & Analysis unit $\begin{array}{c}\text { Instrument or } \\
\text { technique to use }\end{array}$ \\
\hline & 1 & $\leq 6$ & Very low & & \\
Dynamic & 2 & $7-10$ & Low & & \\
Strength Capacity & 3 & $11-13$ & Lower than average & & \\
of the abdomen & 4 & $14-17$ & Half & 120 People & Strength test \\
in women. & 5 & $18-20$ & Above average & & \\
& 6 & $21-23$ & High & & \\
& 7 & $>24$ & Very high & \\
\hline
\end{tabular}


Table 4. Variable of dynamic abdominal force in men.

\begin{tabular}{lccccc}
\hline Variables & Dimensions & Indicator & Items & Analysis unit $\begin{array}{c}\text { Instrument or } \\
\text { technique to use }\end{array}$ \\
\hline & 1 & $\leq 9$ & Very low & & \\
Dynamic & 2 & $10-13$ & low & & \\
Strength Capacity & 3 & $14-15$ & Lower than average & & \\
of the abdomen & 4 & $16-18$ & half & 200 people & Strength test \\
in men & 5 & $19-21$ & Above average & & \\
& 6 & $22-24$ & High & & \\
& 7 & $>25$ & Very high & \\
\hline
\end{tabular}

Table 5 Conditional Test of Dynamic Arm Force. (Harvest) Woman.

\begin{tabular}{lccc}
\hline 20-second faucet test (Woman). Quantity & & \\
\hline Rank & Level in number & Level in letters & Points \\
\hline$\leq 7$ & 1 & Very low & 4 \\
$8-10$ & 2 & Low & 5 \\
$11-12$ & 3 & Lower than average & 6 \\
$13-14$ & 4 & Half & 7 \\
$15-16$ & 5 & Above average & 8 \\
$17-18$ & 6 & High & 9 \\
$>19$ & 7 & Very high & 10 \\
\hline
\end{tabular}

Table 6. Conditional Test of Dynamic Arm Force. (Harvest) Men.

\begin{tabular}{lccc}
\hline 20-second faucet test (Men). Quantity & & \\
\hline Rank & Level in number & Level in letters & Points \\
\hline$\leq 3$ & 1 & Very low & 4 \\
$4-7$ & 2 & Low & 5 \\
$8-9$ & 3 & Lower than average & 6 \\
$10-14$ & 4 & Half & 7 \\
$15-16$ & 5 & Above average & 8 \\
$17-21$ & 6 & High & 9 \\
$>22$ & 7 & Very high & 10 \\
\hline
\end{tabular}

Table 7. Conditional Test of Dynamic Abdomen Strength for women (Collection).

\begin{tabular}{lccc}
\hline \multicolumn{3}{l}{ Abs test in 20 seconds (Woman) } & \\
\hline Rank & Level in number & Level in letters & Points \\
\hline$\leq 6$ & 1 & Very low & 4 \\
$7-10$ & 2 & Low & 5 \\
$11-13$ & 3 & Lower than average & 6 \\
$14-17$ & 4 & Half & 7 \\
$18-20$ & 5 & Above average & 8 \\
$21-23$ & 6 & High & 9 \\
$>24$ & 7 & Very high & 10 \\
\hline
\end{tabular}


Table 8. Conditional Test of Dynamic Abdomen Strength for men (Collection).

\begin{tabular}{lccc}
\multicolumn{4}{l}{ Abs test in 20 seconds (Men) } \\
\hline Rank & Level in number & Level in letters & Points \\
\hline$\leq 9$ & 1 & Very low & 4 \\
$10-13$ & 2 & Low & 5 \\
$14-15$ & 3 & Lower than average & 6 \\
$16-18$ & 4 & Half & 7 \\
$19-21$ & 5 & Above average & 8 \\
$22-24$ & 6 & High & 9 \\
$>25$ & 7 & Very high & 10 \\
\hline
\end{tabular}

Table 9. Conditional Test of Speed of Translation Women (Harvest).

\begin{tabular}{lccc}
\hline \multicolumn{4}{l}{ Translation speed test 27 meters (Woman). Seconds } \\
\hline Rank & Level in number & Level in letters & Points \\
\hline$\leq 4.53$ & 7 & Very high & 10 \\
$4.54-5.89$ & 6 & High & 9 \\
$5.90-6.57$ & 5 & Above average & 8 \\
$6.58-7.93$ & 4 & Half & 7 \\
$7.94-8.61$ & 3 & Lower than average & 6 \\
$8.62-9.97$ & 2 & Low & 5 \\
$\geq 9.98$ & 1 & Very low & 4 \\
\hline
\end{tabular}

Table 10. Conditional Test of Speed of Translation Men (Harvest).

\begin{tabular}{lccc}
\hline \multicolumn{1}{l}{ Translation speed test $\mathbf{2 7}$ meters (Men). Seconds } & & \\
\hline Rank & Level in number & Level in letters & Points \\
\hline$\leq 5.6$ & 7 & Very high & 10 \\
$5.61-6.13$ & 6 & High & 9 \\
$6.14-6.40$ & 5 & Above average & 8 \\
$6.41-6.92$ & 4 & Half & 7 \\
$6.93-7.19$ & 3 & Lower than average & 6 \\
$7.20-7.72$ & 2 & Low & 5 \\
$\geq 7.73$ & 1 & Very low & 4 \\
\hline
\end{tabular}

Instrument procedure for validation for theoretical validation of the set of physical exercises.

The Chanlat Matrix will allow competent specialists to identify the potentialities and insufficiencies of any proposal that is built, from a theoretical framework of science, therefore it is applicable to a set of physical exercises appropriate to the operation of the load (volume and intensity) to contribute to the improvement of the conditional capacities in seventh grade students of the Pedro Nufio Technical Vocational Institute of Danlí. Said capacities will be the Abdomen Force, Arm Force and Translation Speed.

The objective: The application of this technique in the research consists of: Analysing the effects of a set of physical exercises to improve the conditional capacities in seventh grade students of the Pedro Nufio Technical Vocational Institute of Danlí.

To calculate the Effects of the Set of Physical Exercises (ECEF), the following formula is used:

E.C.E. F = I F x O / 100 (Impact, Functionality, Opportunity). 
According to the referred authors, scholars and creators of the Chanlat matrix, the classification of the results of the ECEF in the following ranges are used:

- If ECEF is greater than 8, the proposal is considered strong.

- If ECEF is between 5 and 7 , the proposal is considered medium.

- If ECEF is less than 5 , the proposal is considered weak.

To achieve this application of the Chanlat Matrix method, 10 specialists from the area of Physical Culture and Sport will be interviewed in relation to the Training of conditional physical capacities through Physical Education Classes, their academic level was identified, the functions they perform, the years as a worker in the area and the experience in its specialty.

The selection of specialists will be made using the following criteria:

- Degree in the area of Physical Culture (Degree in Physical Education, Sports and Sports Training).

- Graduates or graduates of academic training processes in the area of Physical Culture (Graduates in Physical Education, Sports Trainers and Physical Trainers).

- At least 5 years of experience as a Physical Education teacher, Coach or Physical Trainer.

The systematization of research associated with the direction and teaching of physical education, sports training, the elaboration of the proposal and the measurement of results of these alternatives within Physical Culture and Sports, will allow the identification of variables and indicators submitted to the evaluation and suggestions requested by applying the Chanlat matrix.

Table 11. Chanlat matrix. (Validation).

\begin{tabular}{|l|l|l|}
\hline $\begin{array}{l}\text { Dimensions of the } \\
\text { Physical Exercise } \\
\text { Program variable }\end{array}$ & Indicators & Qualification \\
\hline \multirow{5}{*}{ 1.- Impact (I) } & $\begin{array}{l}\text { 1.- Contributes to the achievement of the objectives of the set } \\
\text { of exercises. }\end{array}$ & \\
\hline $\begin{array}{l}\text { 2.- Satisfies the planning needs of the set of exercises. } \\
\text { 3.- Covers the basic needs on the planning of the set of } \\
\text { exercises. }\end{array}$ & \\
\hline $\begin{array}{l}\text { 4.- Contains an adequate organization of the set of exercises. } \\
\text { 2.- Functionality (F) }\end{array}$ & $\begin{array}{l}\text { 1.- There is applicability of the plan of the set of exercises. } \\
\text { 2.- It has the necessary resources for the process of executing } \\
\text { the set of exercises. }\end{array}$ & \\
\hline & $\begin{array}{l}\text { 3.- There is official support from the authorities of the } \\
\text { institution involved in developing the set of exercises. }\end{array}$ & \\
\hline $\begin{array}{l}\text { 4.- It has the quality with respect to the distribution of the } \\
\text { components of the set of exercises. }\end{array}$ & \\
\hline $\begin{array}{l}\text { 5.- Feasibility of developing the set of exercises. } \\
\text { 1.- The demands of the environment that favour the set of } \\
\text { exercises. }\end{array}$ & \\
\hline 2.- The set of exercises is desirable. & \\
\hline 3.- There is a need for the set of exercises. & \\
\hline $\begin{array}{l}\text { 4.- There is general support for the development of the set of } \\
\text { exercises. }\end{array}$ & \\
\hline
\end{tabular}




\section{RESULTS}

Tabulation and compilation of the data provided by the Chanlat Matrix.

Step 1. Filling in the data table provided by each of the specialists in the research topic.

Step 2. Each of the scores given by each specialist are added to each indicator that presents the three dimensions of the variable.

Example: Dimensions; Impact (I) (Indicators 1, 2, 3 and 4), Functionality (F) (Indicators 1, 2, 3, 4 and 5) and Opportunity (O) (Indicators 1, 2, 3 and 4)

Sum Weighting: Specialist 1

$$
\begin{aligned}
& I=10+9+8+10=37 \\
& F=9+10+10+10+9=48 \\
& O=8+9+10+10=37
\end{aligned}
$$

Step 3. The Weighting is divided by the number of indicators that each dimension has:

Example: $\mathrm{I}=37 / 4=9.25$

\begin{tabular}{|c|c|c|c|c|c|c|c|c|c|c|c|c|c|c|c|c|c|c|c|}
\hline \multirow{4}{*}{$\begin{array}{l}\text { No. of } \\
\text { Specialist }\end{array}$} & \multicolumn{17}{|c|}{ Dimensions of the Variable Set of Physical Exercises } & \multirow{4}{*}{$\begin{array}{l}\mathbf{P} \\
\text { Total }\end{array}$} & \multirow{4}{*}{$\mathbf{P}$} \\
\hline & \multirow{2}{*}{\multicolumn{4}{|c|}{$\begin{array}{l}\text { Impact. (I) } \\
\text { Indicators }\end{array}$}} & \multirow{3}{*}{$\begin{array}{l}\mathrm{P} \\
\text { Tota }\end{array}$} & \multirow{3}{*}{$P$} & \multirow{2}{*}{\multicolumn{5}{|c|}{$\begin{array}{c}\text { Functionality. (F) } \\
\text { Indicators }\end{array}$}} & \multirow{3}{*}{$\begin{array}{c}P \\
\text { Total }\end{array}$} & \multirow{3}{*}{$P$} & \multirow{2}{*}{\multicolumn{4}{|c|}{$\begin{array}{c}\text { Opportunity }(\mathrm{O}) \\
\text { Indicators }\end{array}$}} & & \\
\hline & & & & & & & & & & & & & & & & & & & \\
\hline & 1 & 2 & 3 & 4 & & & 1 & 2 & 3 & 4 & 5 & & & 1 & 2 & 3 & 4 & & \\
\hline 1 & 9 & 9 & 8 & 9 & 35 & 8.75 & 10 & 9 & 9 & 10 & 9 & 47 & 9.40 & 10 & 9 & 9 & 9 & 37 & 9.25 \\
\hline 2 & 10 & 8 & 8 & 9 & 35 & 8.75 & 10 & 9 & 9 & 9 & 9 & 46 & 9.20 & 9 & 10 & 10 & 9 & 38 & 9.50 \\
\hline 3 & 9 & 9 & 9 & 8 & 35 & 8.75 & 10 & 9 & 9 & 10 & 9 & 47 & 9.40 & 9 & 9 & 10 & 9 & 37 & 9.25 \\
\hline 4 & 10 & 9 & 8 & 8 & 35 & 8.75 & 9 & 10 & 9 & 10 & 9 & 47 & 9.40 & 10 & 9 & 9 & 10 & 38 & 9.50 \\
\hline 5 & 9 & 8 & 9 & 9 & 35 & 8.75 & 9 & 9 & 9 & 10 & 9 & 46 & 9.20 & 10 & 9 & 9 & 10 & 38 & 9.50 \\
\hline 6 & 10 & 8 & 8 & 8 & 34 & 8.50 & 10 & 9 & 9 & 10 & 9 & 47 & 9.40 & 10 & 10 & 9 & 9 & 38 & 9.50 \\
\hline 7 & 10 & 9 & 8 & 9 & 36 & 9.00 & 10 & 9 & 9 & 9 & 9 & 46 & 9.20 & 10 & 9 & 9 & 9 & 37 & 9.25 \\
\hline 8 & 10 & 9 & 9 & 8 & 36 & 9.00 & 10 & 9 & 9 & 9 & 9 & 46 & 9.20 & 10 & 9 & 9 & 9 & 37 & 9.25 \\
\hline 9 & 10 & 9 & 8 & 8 & 35 & 8.75 & 9 & 9 & 9 & 10 & 9 & 46 & 9.20 & 10 & 10 & 9 & 9 & 38 & 9.50 \\
\hline 10 & 9 & 9 & 9 & 8 & 35 & 8.75 & 10 & 10 & 8 & 10 & 9 & 47 & 9.40 & 10 & 9 & 9 & 9 & 37 & 9.25 \\
\hline
\end{tabular}

$$
\begin{aligned}
& F=48 / 5=9.6 \\
& O=37 / 4=9.25
\end{aligned}
$$

Table 12. Shows the data tabulated and collected by specialists specifically by indicators.

Step 4. Validation results from consultations with specialists using the Chanlat matrix.

Formula: The Expected Effectiveness of the Physical Exercise Set (ECEF) Legend: $P=$ Weighting. $P \square=$ Average Weighting.

$\mathrm{ECEF}=\mid \times F \times 0=$

100

Example Specialist 1: ECEF $=9.25 \times 9.6 \times 9.25=8.21$

$$
100
$$


Table 13. Show the tabulated and collected data from the specialists for this investigation generally by variable.

\begin{tabular}{|l|l|l|l|l|}
\hline \multirow{2}{*}{ No. of Specialist } & \multicolumn{3}{|c|}{ Variable } & \multirow{2}{*}{ Total } \\
\cline { 2 - 4 } & Impact. (I) Weighing & Functionality (F) Weighing & Opportunity. (O) Weighing & \\
\hline 1 & 8.75 & 9.40 & 9.25 & 7.61 \\
\hline 2 & 8.75 & 9.20 & 9.50 & 7.65 \\
\hline 3 & 8.75 & 9.40 & 9.25 & 7.61 \\
\hline 4 & 8.75 & 9.40 & 9.50 & 7.81 \\
\hline 5 & 8.75 & 9.20 & 9.50 & 7.65 \\
\hline 6 & 8.50 & 9.40 & 9.50 & 7.59 \\
\hline 7 & 9.00 & 9.20 & 9.25 & 7.66 \\
\hline 8 & 9.00 & 9.20 & 9.25 & 7.66 \\
\hline 9 & 8.75 & 9.20 & 9.50 & 7.65 \\
\hline 10 & 8.75 & 9.40 & 9.25 & 7.61 \\
\hline
\end{tabular}

Step 5. Sum of Average Weights.

Example: $\sum \mathrm{P}$ / No. Of Specialist (10)

$\sum \mathrm{P}=7.61+7.65+7.61+7.81+7.65+7.59+7.66+7.66+7.65+7.61=$ 10

7.65 The Proposal is considered Medium.

Table 14. Conditional Test of Dynamic Arm Force. Women (Collection).

\begin{tabular}{lccc}
\hline 20-second faucet test (Women). Quantity & & \\
\hline Rank & Level in number & Level in letters & Points \\
\hline$\leq 7$ & 1 & Very low & 4 \\
$8-10$ & 2 & Low & 5 \\
$11-12$ & 3 & Lower than average & 6 \\
$13-14$ & 4 & Half & 7 \\
$15-16$ & 5 & Above average & 8 \\
$17-18$ & 6 & High & 9 \\
$\geq 19$ & 7 & Very high & 10 \\
\hline
\end{tabular}

Table 15. Conditional Test of Dynamic Arm Force. Men (Collection).

\section{0-second faucet test (Men). Quantity}

\begin{tabular}{lccc}
\hline Rank & Level in number & Level in letters & Points \\
\hline$\leq 3$ & 1 & Very low & 4 \\
$4-7$ & 2 & Low & 5 \\
$8-9$ & 3 & Lower than average & 6 \\
$10-14$ & 4 & Half & 7 \\
$15-16$ & 5 & Above average & 8 \\
$17-21$ & 6 & High & 9 \\
$\geq 22$ & 7 & Very high & 10 \\
\hline
\end{tabular}


Table 16. Conditional Test of Dynamic Abdomen Strength. Females (Collection).

\begin{tabular}{lccc}
\hline \multicolumn{3}{l}{ Abs test in 20 seconds (Women) } & \\
\hline Rank & Level in number & Level in letters & Points \\
\hline$\leq 6$ & 1 & Very low & 4 \\
$7-10$ & 2 & Low & 5 \\
$11-13$ & 3 & Lower than average & 6 \\
$14-17$ & 4 & Half & 7 \\
$18-20$ & 5 & Above average & 8 \\
$21-23$ & 6 & High & 9 \\
$\geq 24$ & 7 & Very High & 10 \\
\hline
\end{tabular}

Table 17. Conditional Test of Dynamic Abdomen Strength. Men (Collection).

\begin{tabular}{lccc}
\hline Abs test in 20 seconds (Men) & & \\
\hline Rank & Level in number & Level in letters & Points \\
\hline$\leq 9$ & 1 & Very low & 4 \\
$10-13$ & 2 & Low & 5 \\
$14-15$ & 3 & Lower than average & 6 \\
$16-18$ & 4 & Half & 7 \\
$19-21$ & 5 & Above average & 8 \\
$22-24$ & 6 & High & 9 \\
$\geq 25$ & 7 & Very High & 10 \\
\hline
\end{tabular}

Table 18. Conditional Test of Speed of Translation. Females (Collection).

\begin{tabular}{lccc}
\hline \multicolumn{1}{l}{ Translation speed test $\mathbf{2 7}$ meters (Women). Seconds } & & \\
\hline Rank & Level in number & Level in letters & Points \\
\hline$\leq 4.53$ & 7 & Very high & 10 \\
$4.54-5.89$ & 6 & high & 9 \\
$5.90-6.57$ & 5 & Above average & 8 \\
$6.58-7.93$ & 4 & Half & 7 \\
$7.94-8.61$ & 3 & Lower than average & 6 \\
$8.62-9.97$ & 2 & Low & 5 \\
$\geq 9.98$ & 1 & Very low & 4 \\
\hline
\end{tabular}

Table 19. Conditional Test of Speed of Translation. Females (Collection).

\begin{tabular}{lccc}
\hline \multicolumn{3}{l}{ Translation speed test 27 meters (Men). Seconds } & \\
\hline Rank & Level in number & Level in letters & Points \\
\hline$\leq 5.6$ & 7 & Very high & 10 \\
$5.61-6.13$ & 6 & high & 9 \\
$6.14-6.40$ & 5 & Above average & 8 \\
$6.41-6.92$ & 4 & Half & 7 \\
$6.93-7.19$ & 3 & Lower than average & 6 \\
$7.20-7.72$ & 2 & Low & 5 \\
$\geq 7.73$ & 1 & Very Low & 4 \\
\hline
\end{tabular}


Table 20. Data obtained from the pre and post-test of the seventh 1 regarding the capacities evaluated and applied tests.

\begin{tabular}{lccccccc}
\hline Physical ability & Decreased & $\%$ & They kept & $\%$ & Were up & $\%$ & Total Students \\
\hline Abdominal strength & 2 & 5.8 & 0 & 0 & 32 & 94.2 & 34 \\
Arm force & 6 & 17.6 & 0 & 0 & 28 & 82.4 & 34 \\
Translation speed & 5 & 14.7 & 0 & 0 & 29 & 85.3 & 34 \\
\hline
\end{tabular}

The physical capacities worked in the seventh grade section 1, in 10 weeks of intervention (40 hours of work) generated the following result: According to the measurements carried out in the pre-test and afterwards, apply a set of exercises to contribute to the improvement of capacities diagnosed in the post-test, it was possible to show that in abdominal strength, 2 students decreased their capacity, which represents $5.88 \%$ and 32 students increased their capacity, representing $94.11 \%$. In arm strength, their capacity decreased 6 , representing $17.64 \%$, and 28 increased, representing $82.35 \%$. In the translation speed capacity, 5 decreased their capacity, which represents $14.7 \%$, and 29 increased their capacity, which represents $85.29 \%$.

In the post-test, it was possible to show that in abdominal strength, 5 students decreased their capacity, which represents $12.5 \%$, and 35 students increased their capacity, which represents 87.5 . In arm strength, their capacity decreased by 5 , which represents $12.5 \%$ and increased by 35 , which represents $87.5 \%$. In the capacity of speed of translation 7 they decreased their capacity that represents $17 \%$ and $33 \%$ increased their capacity that represents $82.5 \%$.

Table 21. Data obtained from the pre and post-test of the seventh 3 regarding the capacities evaluated and applied tests.

\begin{tabular}{lccccccc}
\hline Physical ability & Decreased & $\%$ & They kept & $\%$ & Were up & $\%$ & Total Students \\
\hline Abdominal strength & 3 & 7.14 & 0 & 0 & 39 & 92.85 & 42 \\
Arm force & 3 & 7.14 & 0 & 0 & 39 & 92.85 & 42 \\
Translation speed & 3 & 7.14 & 0 & 0 & 39 & 92.85 & 42 \\
\hline
\end{tabular}

According to the measurement carried out in the pre-test and afterwards, apply a set of exercises to contribute to the improvement of capacities diagnosed in the post-test, it was possible to show that in the abdominal strength 3 students decreased their capacity, which represents $7.14 \%$ and increased its capacity 39 students that represents $92.85 \%$. In arm strength, their capacity decreased 3, representing $7.14 \%$ and 39 , representing $92.85 \%$. In the capacity of speed of translation 3 decreased their capacity that represents $7.14 \%$ and 39 increased their capacity that represents $92.85 \%$.

Table 22. Data obtained from the pre and post-test of the seventh 4 regarding the capacities evaluated and applied tests.

\begin{tabular}{lccccccc}
\hline Physical ability & Decreased & $\%$ & They kept & $\%$ & Were up & $\%$ & Total Students \\
\hline Abdominal strength & 2 & 5 & 0 & 0 & 38 & 95 & 40 \\
Arm force & 3 & 7.5 & 0 & 0 & 37 & 92.5 & \\
Translation speed & 7 & 17.5 & 0 & 0 & 33 & 82.5 & \\
\hline
\end{tabular}

In section 4, the pre-test and then the application of a set of exercises to contribute to the improvement of capacities diagnosed in the post-test, it was possible to show that in abdominal strength, 2 students decreased their capacity, which represents $5 \%$ and increased their capacity 38 students that represents $95 \%$. In arm strength, their capacity decreased 3 , representing $7.5 \%$, and 37 increased, representing $92.5 \%$. In 
the translation speed capacity, 7 decreased their capacity, which represents $17.5 \%$, and 33 increased their capacity, which represents $82.5 \%$.

Table 23. Data obtained from the pre and post-test of the seventh 5 regarding the capacities evaluated and applied tests.

\begin{tabular}{lccccccc}
\hline Physical ability & Decreased & $\%$ & They kept & $\%$ & Were up & $\%$ & Total Students \\
\hline Abdominal strength & 5 & 11.9 & 0 & 0 & 37 & 88.05 & 42 \\
Arm force & 9 & 24.42 & 0 & 0 & 33 & 78.57 & \\
Translation speed & 7 & 16.66 & 0 & 0 & 35 & 83.33 & \\
\hline
\end{tabular}

The seventh grade section 5, in 10 weeks of intervention (40 hours of work) generated the following result: According to the measurement carried out in the pre-test and afterwards, apply a set of exercises to contribute to the improvement of capacities diagnosed in the post test it was possible to show that in abdominal strength, 5 students decreased their capacity, representing 11.9\%, and 37 students increased their capacity, representing $88.5 \%$. In arm strength, their capacity decreased 9, representing $24.42 \%$, and 33 increased, representing $78.57 \%$. In the capacity of speed of translation 7 decreased their capacity that represents $16.66 \%$ and 35 increased their capacity that represents $83.33 \%$.

Table 24. Data obtained from the pre and post-test of the seventh 6 regarding the capacities evaluated and applied tests.

\begin{tabular}{lccccccc}
\hline Physical ability & Decreased & $\%$ & They kept & $\%$ & Were up & $\%$ & Total Students \\
\hline Abdominal strength & 2 & 5.26 & 1 & 2.63 & 35 & 92.1 & 38 \\
Arm force & 6 & 15.78 & 1 & 2.63 & 31 & 81.57 & \\
Translation speed & 7 & 18.42 & 1 & 5.26 & 29 & 76.31 & \\
\hline
\end{tabular}

In the seventh grade section 6 , in 10 weeks of intervention (40 hours of work) they generated the following result: According to the measurements carried out in the pre-test and afterwards, apply a set of exercises to contribute to the improvement of capacities diagnosed in the Post test it was possible to show that in abdominal strength, 2 students decreased their capacity, representing 5.6\%, maintained 1, representing $2.63 \%$, and 35 students increased their capacity, representing $92.1 \%$. In arm strength, their capacity decreased 6 , representing $15.78 \%$, maintained 1 , representing $2.63 \%$, and increased by 31 , representing $81.57 \%$. In the capacity of speed of translation 7 decreased their capacity that represents $18.42 \%$, they maintained 2 that represents $5.26 \%$ and 29 increased their capacity that represents $76.31 \%$

\section{DISCUSSION AND CONCLUSIONS}

The results of the systematization carried out by several authors in the selected bibliography on the subject of interest (Physical Capabilities) led us to the structuring of the exercises that allowed us to determine that the systematicity in the exercise of them is a fundamental aspect for the development of the body human.

The physical exercises applied in 10 weeks (40 hours of work) contributed greatly to improve the physical capacities in experiment (arm strength, abdominal strength and speed of translation) since in the three capacities subjected to the investigation more than $85 \%$ of the learners improved their ability and less than $15 \%$ maintained or decreased their physical ability. 
The application of the principles of Physical Culture contributed to a great extent so that physical exercises contributed to improving physical capacities to a great extent because after the intervention the difference between the pre-test and the post-test is observed.

The validation by experts generates an interesting piece of information, and that is that it considers the proposal at a medium level, an aspect that coincides, since improving the physical capacities investigated in $85 \%$ of the study population indicates that we must improve the exercises or increase the number of hours in exercise.

\section{REFERENCES}

Alvarez, P (2006) "Terminology of gymnastics". Mimeography material. Gymnastics Department. ISCF "Manuel Fajardo". Havana.

Aschwer, H. (2000). Triathlon training. Barcelona, Spain: Editorial Paidotribo.

Barrios J., Ranzola. A. (2000) Manual for Sports Development Initiation. Havana, Cuba: Editorial. Sports.

Doval, F (1996). My Body and the Movement for the students of Mexico. Chapter corresponding to the development of physical capacities. (Grades 5 and 6 of primary, Grade 9 of secondary). Mexico: Editorial Alegre Juventud.

Fernández, L. (2003) Qualities and Motor Skills, Efdeportes.com Magazine. Recovered. www.efdeportes.com

Hernández, Y (2018). www.pedronufioblogspot.com. Pedro Nufio Vocational Institute.

López, U. (2005) Conditional physical capacities and health in secondary school adolescents.

Platonov, V. (2001). Sports training theory and methodology. Barcelona, Spain: Editorial Pardotribo 6th edition.

Ruiz A. (2004). Methodology of teaching physical education. La Habana Editorial Pueblo y Educación.

Ruiz A. \& Cols (2005). Methodology of teaching physical education. Volumes I and II, Editorial Pueblo y Educación, Havana.

Weineck J. (2007). Optimal training. Europea, Barcelona: Editorial Hispano.

Zintl F. (2009). Resistance training. México: Ediciones Roca S.A.

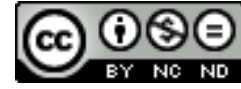

This work is licensed under a Attribution-NonCommercial-NoDerivatives 4.0 International (CC BY-NC-ND 4.0). 